\title{
Intensity-Modulated Radiotherapy in Patients with Cervical Cancer. An intra-individual Comparison of Prone and Supine Positioning
}

\author{
Carmen Stromberger*1, Yves Kom¹, Michael Kawgan-Kagan1', Tristan Mensing1', Ulrich Jahn1, Achim Schneider2, \\ Volker Budach', Christhardt Köhler² and Simone Marnitz*1
}

\begin{abstract}
Background: Chemoradiation for cervical cancer patients is associated with considerable gastrointestinal toxicity. Intensity-modulated radiotherapy (IMRT) has demonstrated superiority in terms of target coverage and normal tissue sparing in comparison to conventional 3D planning in gynaecological malignancies. Whether IMRT in prone (PP) or supine position (SP) might be beneficial for cervical cancer patients remains partially unanswered.

Methods: 10 patients on FIGO stage IB-III cervical cancer, 6 patients for definitive and 4 patients for adjuvant external beam pelvic RT, were planned in PP and SP using a 7-field IMRT technique. IMRT plans for PP and SP (mean dose, $\mathrm{D}_{\text {mean }}$ $50.4 \mathrm{~Gy}$ ) were optimized in terms of PTV coverage (1 st priority) and small bowel sparing ( $2^{\text {nd }}$ priority). A comparison of DVH parameters for PTV, small bowel, bladder, and rectum was performed.

Results: The comparison showed a similar PTV coverage of $95 \%$ of the prescribed dose and for target conformity in IMRT plans (PP, SP). PTV, rectum and bladder volumes were comparable for PP and SP. Significantly larger volumes of small bowel were found in PP $(436 \mathrm{cc},+35 \%, \mathrm{p}=0.01)$. PP decreased the volume of small bowel at 20-50.4 Gy $(\mathrm{p}<0.05)$ and increased the rectum volumes covered by doses from 10-40 Gy $(p<0.01)$, the V50.4 was $<5 \%$ in both treatment positions. Bladder sparing was significant better at $50.4 \mathrm{~Gy}(\mathrm{p}=0.03)$ for PP.

Conclusion: In this dosimetric study, we demonstrated that pelvic IMRT in prone position for patients with cervical cancer seems to be beneficial in reducing small bowel volume at doses $\geq 20$ Gy while providing similar target coverage and target conformity. The use of frequent image guidance with KV (kilovolt) or MV (megavolt) computertomography can reduce set-up deviations, and treatment in prone position can be done with a higher set-up accuracy. Clinical outcome studies are needed to affirm lower toxicity.
\end{abstract}

\section{Background}

Chemoradiation is the treatment of choice in locally advanced, lymph node positive and/or high-risk cervical cancer patients [1-9]. The treatment is associated with considerable gastrointestinal, genitourinary, and haematological toxicity $[10,11]$. Furthermore, the combination of radical hysterectomy and adjuvant radiation leads to an increase of therapy related toxicity [12,13]. In order to cover tumour and locoregional lymph nodes adequately with a 2-D or 3-D conformal radiotherapy technique,

*Correspondence: carmen.stromberger@charite.de, simone.marnitz@charite.de Department of Radiooncology, Charité University Hospital, Campus CCM and CVK, Augustenburger Platz 1, 13353 Berlin, Germany

Full list of author information is available at the end of the article large portions of small bowel must be included in the radiation ports. The incidence and severity of gastrointestinal morbidity depends on the volume of small bowel and on the radiation dose to the small bowel and correlates with a pelvic surgery prior to radiotherapy [14-17]. In the past, efforts were made to reduce the incidence and severity of gastrointestinal toxicity. Pelvic radiotherapy in prone position on a belly-board device resulted in a significant sparing of small bowel [18-23]. A recent study showed that patient set-up in prone position is subject to larger systematic errors, but the set-up in supine position harbours larger random errors [24]. A superiority of intensity-modulated radiotherapy (IMRT) over conventional 3-D planning has been demonstrated for gynaeco- 
logical malignancies in terms of target coverage and normal tissue sparing [25-29]. Furthermore, IMRT offers the possibility of dose escalation without increased therapy related toxicity [30,31]. Dose escalation with a simultaneous integrated boost is even feasible in patients with advanced cervical cancer [32]. Even though oncological results for IMRT seem to be similar to those for 3-D planning [33-35], issues concerning the optimal margins, tumour regression, movement of organs at risk during the course of radiotherapy and the optimal treatment position remain a challenging field of research. In this study, we assess whether a pelvic 7-field IMRT in prone or supine position can be more efficient regarding the sparing of small bowel, rectum and bladder in patients with cervical cancer.

\section{Methods}

\section{Patients}

10 patients with histological confirmed cervical cancer on FIGO stage IB1, IB2, IIB and IIIB were selected for this study. 6 patients were treated with definitive chemoradiation (FIGO stage: IB1 in 2 patients, IB2, IIA, IIB and IIIB each in one patient). All of these patients underwent transperitoneal laparoscopic pelvic and paraaortic lymphadenectomy as described previously [36]. Pelvic lymph node metastases were confirmed in all of these patients. 4 patients (FIGO stage: IB1 in 3, and IIB in 1 patient) received an adjuvant chemoradiation. All patients had an abdominal radical hysterectomy and a pelvic lymphadenectomy. Prior to therapy, a chest X-ray and abdominal ultrasound was performed to exclude distant metastases.

\section{Imaging}

For each patient, two consecutive treatment planning CT scans (CT scanner LightSpeed from GE Healthcare, General Electric Company, NYSE; GE), from the diaphragm to the trochanter minor with a slice thickness of $3.75 \mathrm{~mm}$. were performed. The $\mathrm{CT}$ was performed with a belly board in prone position (PP), and with a head rest, a knee and ankle fixation in the supine position (SP). No instructions for bladder or rectum filling were given. The CT scans were acquired during a period when both scans were routinely carried out for patients with a high risk for paraaortic metastases, in order to switch the treatment technique easily if paraaortic metastases were histologically confirmed. Intravenous contrast mediaum (Xenetix $350^{\circ}$ ) and a vaginal tampon soaked in contrast medium were used to aid the delineation; oral contrast media was not used obligatorally.

\section{Target volumes and organs at risk}

According to the recommendations of the International Commission on Radiation Units and Measurements Reports (ICRU) 50 and 62, target volumes and organs at risk were delineated in all axial CT slices $[37,38]$. For definitive treatment, the gross tumour volume (GTV) was defined as the macroscopic tumour, including the cervix with visible tumour extension and the corpus uteri. The clinical target volume (CTV) was defined by adding $5 \mathrm{~mm}$ to the GTV. Additionally, the external, internal and common iliacs and the presacral lymph nodes were included according to the RTOG recommendations [39]. For postoperative treatment, the CTV included all regions of potential microscopic disease: the surgical bed, regional lymph node areas (common, external and internal iliacs and the presacral region), and the vaginal cuff. The planning target volume (PTV) was outlined as the CTV plus $1 \mathrm{~cm}$ in all directions. The caudal field border was at the obturator foramen, the upper field border was individualized on the basis of the patient's anatomy to include the common iliac lymph nodes [40]. The bladder, the rectum (sigmoid to anus) and the small bowel (whole peritoneal cavity without lymph nodes, muscles and organs other than small bowel) were outlined as organs at risk. The delineation of the small bowel exceeded the upper and lower border of the PTV by 2 slices to generate comparable volumes. All contours were done by one investigator (C.S.) and review by the senior radiation oncologist (S. M).

\section{Dose Prescription and planning parameters}

The Eclipse Planning Software (Version 7.3.10, Varian, Palo Alto, CA) was used to generate IMRT plans for SP and PP. The prescribed target dose was $5 \times 1.8$ Gy per week, to a total mean dose of $50.4 \mathrm{~Gy}\left(\mathrm{D}_{\text {mean }}\right)$. Treatment was performed on a linear accelerator (Clinac 2300CD, Varian, Palo Alto, CA) with $20 \mathrm{MV}$ photon beams. Planning parameters for the PTV were set to minimize the amount receiving $<95 \%$ of the prescribed dose and the amount receiving $>105 \%$ (52.9 Gy) of the prescribed dose. The second highest priority was given to the sparing of small bowel. Inverse planning input parameters are shown in table 1. Constraints were applied as starting parameters and changed individually for each patient during optimisation. A help structure was generated by applying a $2 \mathrm{~cm}$ ring around the PTV and was used for normal tissue sparing adjacent to the PTV to achieve higher dose conformity.

\section{Radiation Technique}

Treatment planning and the DVH analysis was done with the Eclipse Planning Software (Varian Medical Systems, Palo Alto, CA). IMRT plans were generated based on a seven beam arrangement with beams at $45 / 90 / 115 / 180 /$ 245/280/320 degrees for SP and 0/40/80/115/235/270/ 320 degrees for PP, as is routinely applied at our clinic. The sliding window technique was used. Although patients also received brachytherapy, for this analysis, only external beam irradiation has been taken into account. 
Table 1: Planning parameters

\begin{tabular}{|c|c|c|c|}
\hline Structure & Volume (\%) & Gy & Priority \\
\hline Body & 0 & 54 & $500-800$ \\
\hline \multirow[t]{4}{*}{ PTV } & 0 & 52.9 & 400 \\
\hline & 20 & 50.4 & 200 \\
\hline & 80 & 50.4 & 200 \\
\hline & 100 & 47.9 & 400 \\
\hline Help & 0 & 49 & 100 \\
\hline \multirow[t]{3}{*}{ Small Bowel } & 0 & 50.4 & 100 \\
\hline & 10 & 43 & 150 \\
\hline & 20 & 33 & 150 \\
\hline Bladder & 30 & 50 & 100 \\
\hline Rectum & 25 & 50 & 100 \\
\hline
\end{tabular}

\section{Dose Volume Histogram Analysis}

DVH parameters for the target volume and critical normal tissues were analysed, and the PTV95\% (volume of PTV receiving 95\% of the prescribed dose) and the D1\% (highest dose delivered to $1 \%$ of the PTV) was calculated. The target conformity was calculated according to ICRU reports 50 and 62 (Conformity Index, CI) [37,38] and according to van't Riet and colleagues (Conformity number, CN) [41]. For all IMRT plans and patients set-up positions, the relative volumes (\%) of small bowel, rectum and bladder were evaluated at $10 \mathrm{~Gy}$ (V10), $20 \mathrm{~Gy}$ (V20), 30 Gy (V30), 40 Gy (V40), 45 Gy (V45), and 50.4 Gy (V50.4). The average volumes (cc) and the mean dose $\left(D_{\text {mean }}\right)$ for the PTV and the organs at risk were measured. Dosimetric parameters were compared by the non-parametric Wilcoxon exact signed rank test (SPSS 15.0, Inc., Chicago, IL). Statistical significance was assumed for $\mathrm{p} \leq 0.05$.

\section{Results}

\section{Target Volume}

The mean volume of the PTV was 1227.0 cc (1110.8 $1368.7 \mathrm{cc}$, standard deviation (STD) \pm 66.6 ) for SP and
1369.4 cc (1085.4 - 1703.1 cc, STD \pm 222.1$)$ for PP $(\mathrm{p}=$ 0.6). $\mathrm{D}_{\text {mean }}$ was $50.4 \mathrm{~Gy}$ in PP and SP, respectively. The mean volume of PTV95\% was $97.0 \%(\mathrm{STD} \pm 1.2$ ) for SP and $97.6 \%$ (STD \pm 0.8 ) for PP. The mean D1\% was 52.9 Gy $(\mathrm{STD} \pm 0.2)$ and 52.8 Gy $(\mathrm{STD} \pm 0.2)$ for SP and PP, respectively. The PTV that received $110 \%$ of the prescribed dose was $<0.01 \%$ in both groups. Conformity of IMRT plans for PP and SP IMRT gave similar results (CI: $1.13, \mathrm{STD} \pm 0.08$ vs. $1.11, \mathrm{STD} \pm 0.06$; $\mathrm{CN}: 0.85, \mathrm{STD} \pm$ 0.05 vs. 0.86 , STD \pm 0.05 ). All parameters did not reach statistical significance.

\section{Rectum}

For the SP group, the delineated rectal volume ranged from 48.3 to $94.2 \mathrm{cc}$ (mean volume $71.2 \mathrm{cc}, \mathrm{STD} \pm 18.2$ ) and for the PP group from 52.8 to $174.5 \mathrm{cc}$ (mean volume $96.8 \mathrm{cc}, \mathrm{STD} \pm 34.9 ; \mathrm{p}=0.08)$. In PP, a larger rectal volume was covered by the V10 to V40 ( $\leq 0.01$, Figure 1$)$. Neither the V45 nor the V50.4 or $\mathrm{D}_{\text {mean }}$ (SP: 39.4 Gy, STD \pm 3.5 ; PP: 40.3 Gy, STD \pm 12.5 ; $\mathrm{p}=0.3$ ) showed a statistically significant difference (Table 2).

\section{Bladder}

The bladder volume displayed a highly individual range for both positions. In SP, the bladder volume ranged from 70.7 to $417.7 \mathrm{ml}$, with a mean value of $143.9 \mathrm{ml} \pm 98.3$ (STD), and from 70.2 to $395.2 \mathrm{ml}$, with a mean of 137.0 $\mathrm{ml} \pm$ 93.4 (STD) ( $\mathrm{p}=0.6)$ in PP. The dose-volume histogram for the bladder was significant better in PP at V50.4 $(\mathrm{p}=0.03)$. At V10, V20, V30, V40 and V45, no significant differences were detected (Table 2). $\mathrm{D}_{\text {mean }}$ for SP was 44.2 Gy \pm 2.7 (STD) and $43.1 \mathrm{~Gy} \pm 2.8(\mathrm{STD})(\mathrm{p}=0.7)$ for PP.

\section{Small Bowel}

The small bowel volume varied from 683.8 to 1825.9 cc (mean $1250.6 \mathrm{cc}, \mathrm{STD} \pm 283.0$ ) for SP and from 1193.4 to 2443.9 cc (mean 1686.1 cc, STD \pm 368.7) for PP. Statistically significant larger volumes of small bowel were found in PP $(p=0.01)$. Figure 2a. illustrates the expansion of the peritoneal cavity through the belly board in PP resulting in an anterior movement of the small bowel for these patients. The analysis of the pooled dose-volume histograms showed a significant decrease of the small bowel volume at V20, V30, V40, V45 and V50.4 in favour of the PP ( $<<0.05$, Table 2, Figure 3$)$. $\mathrm{D}_{\text {mean }}$ was 25.9 Gy vs. 30.2 Gy for PP and SP ( $\mathrm{p}=0.049)$, respectively.

\section{Discussion}

Due to an overlap of target structures (lymph nodes) and organs at risk, there is a considerable rate of gastrointestinal and genitourinary morbidity in patients with cervical cancer undergoing pelvic irradiation [10]. With a platinum based chemoradiation, even a radiogenic total 


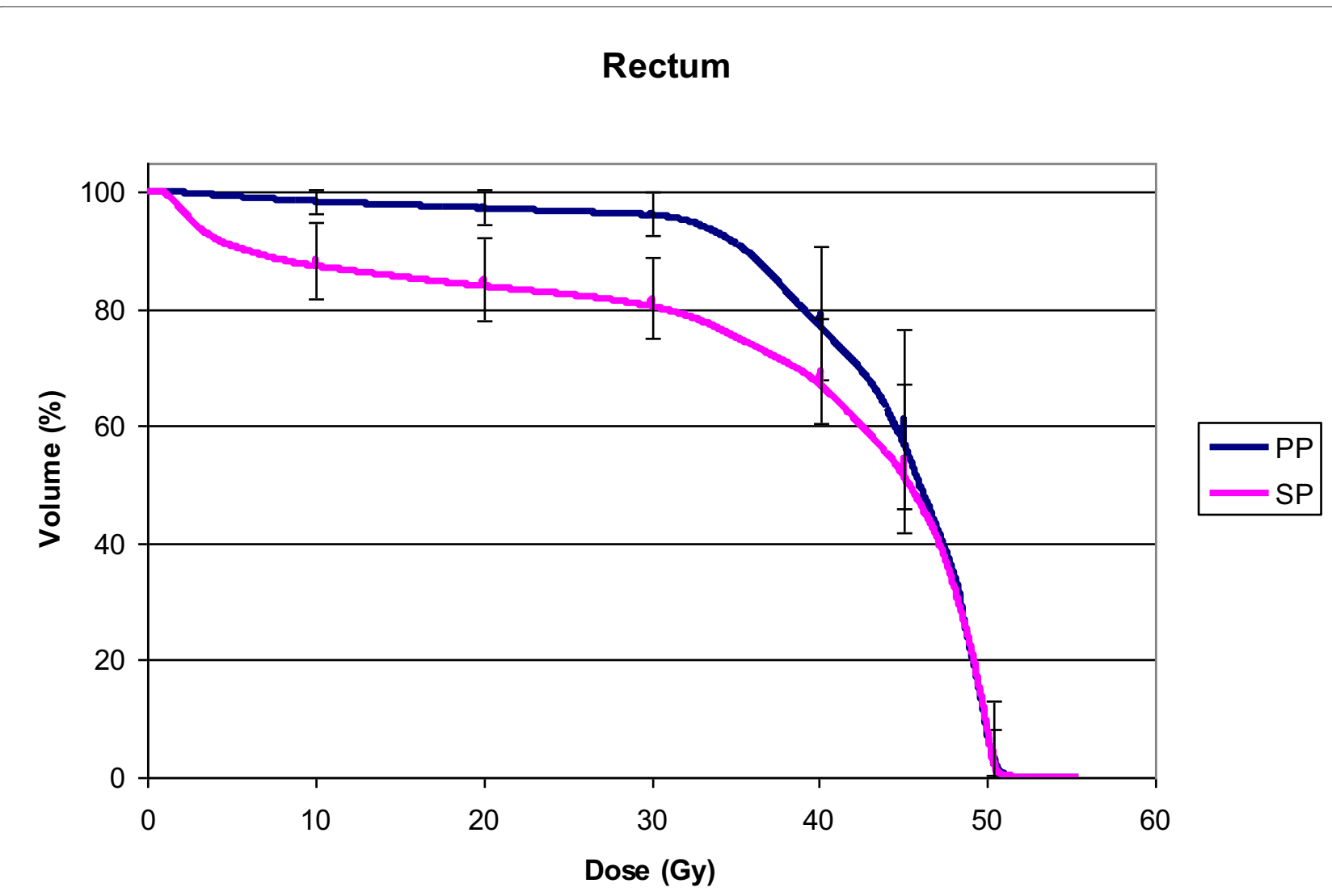

Figure 1 DVH for Rectum. Mean DVH of the rectum in SP (pink) compared to PP (blue). Error bars indicate the standard deviation (STD).

necrosis of the uterus is possible [42]. The risk of developing treatment related side effects depends strongly on the delivered dose, the irradiated volume, and any previous pelvic or abdominal surgery $[11-17,43]$. In the prone position, decreased dose to the small bowel was achieved by using bowel displacement devices [18-23]. The use of IMRT in clinical routine might decrease the risk for acute and late toxicity in patients after pelvic or paraaortic irradiation with comparable outcome [28,29,33,34,44-47]. Although IMRT and treatment in prone position on a belly board holds potential for decreased therapy related gastrointestinal toxicity, the implication of the patient's position when using IMRT has not been systematically investigated. In the 2-D era, Letschert and colleagues [16]

Table 2: DVH statistics

\begin{tabular}{|c|c|c|c|c|c|c|}
\hline & \multicolumn{2}{|c|}{ Small bowel } & \multicolumn{2}{|c|}{ Rectum } & \multicolumn{2}{|c|}{ Bladder } \\
\hline & PP & SP & PP & SP & PP & SP \\
\hline Volume (cc) & $1686.1 \pm 368.7^{*}$ & $1250.6 \pm 283.0$ & $96.8 \pm 34.9$ & $71.2 \pm 18.2$ & $137.0 \pm 93.4$ & $143.9 \pm 98.3$ \\
\hline D mean (Gy) & $25.9 \pm 3^{*}$ & $30.5 \pm 4.5$ & $40.3 \pm 12.5$ & $39.2 \pm 3.5$ & $43.1 \pm 2.8$ & $44.2 \pm 2.7$ \\
\hline V10 (\%) & $91.5 \pm 4.7$ & $92.0 \pm 10.5$ & $98.6 \pm 2.1$ & $88.5 \pm 6.6 *$ & $100.0 \pm 0$ & $99.9 \pm 0.4$ \\
\hline V20 (\%) & $60.4 \pm 11.0 *$ & $76.4 \pm 15.1$ & $97.6 \pm 2.9$ & $85.2 \pm 7.2 *$ & $99.1 \pm 1.9$ & $98.8 \pm 3.7$ \\
\hline V30 (\%) & $32.7 \pm 9.5^{*}$ & $50.4 \pm 13.9$ & $96.5 \pm 3.7$ & $81.9 \pm 7 *$ & $92.1 \pm 7.9$ & $95.5 \pm 7.4$ \\
\hline V40 (\%) & $18.2 \pm 5.8 *$ & $28.4 \pm 7.8$ & $79.4 \pm 11.2$ & $69.5 \pm 8.9 *$ & $72.3 \pm 15.0$ & $77.4 \pm 14.6$ \\
\hline V45 (\%) & $13.7 \pm 4.5^{*}$ & $20.37 \pm 5.5$ & $61.3 \pm 15.3$ & $54.6 \pm 12.7$ & $53.3 \pm 12.8$ & $56.7 \pm 15.0$ \\
\hline V50.4 (\%) & $2.5 \pm 1.2 *$ & $4.0 \pm 1.1$ & $4.2 \pm 4$ & $4.6 \pm 8.3$ & $4.0 \pm 4.6^{*}$ & $12.9 \pm 16.1$ \\
\hline
\end{tabular}

Summary of DVH statistics for SB, rectum, bladder in PP and SP for both IMRT plans, mean values \pm STD. ${ }^{*} \mathrm{p} \leq 0.05$ Wilcoxon signed rank test (exact) SPSS V15. 

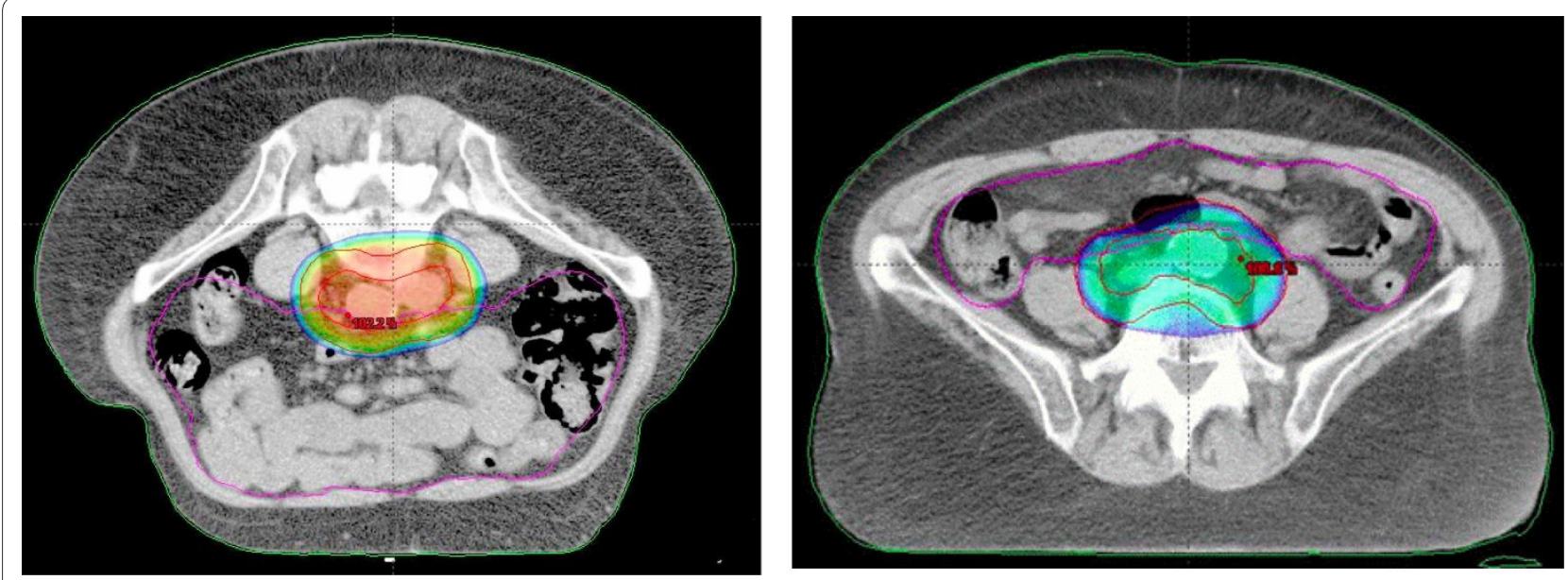

Figure $\mathbf{2}$ a and $\mathbf{b}$ - Expansion of peritioneal cavity. Small bowel movement in PP (left) and SP (right) for the same patient.

found a correspondence between the risk for chronic diarrhoea and malabsorption and the amount of small bowel volume irradiated, but there was no correlation with bowel obstruction. In rectal cancer patients with postoperative pelvic radiotherapy ( $50 \mathrm{~Gy}$ ), the risk for chronic diarrhoea and malabsorption after 5 years was $42 \%$ if the small bowel volume was above 328 cc vs. a risk of $31 \%$ for volumes $<77$ cc [17]. We could reduce the mean small bowel volume receiving $50.4 \mathrm{~Gy}$ to $42 \mathrm{cc}$ (2.5\%) and $50 \mathrm{cc}(4 \%)$ and the V45 to $231 \mathrm{cc}(14 \%)$ and

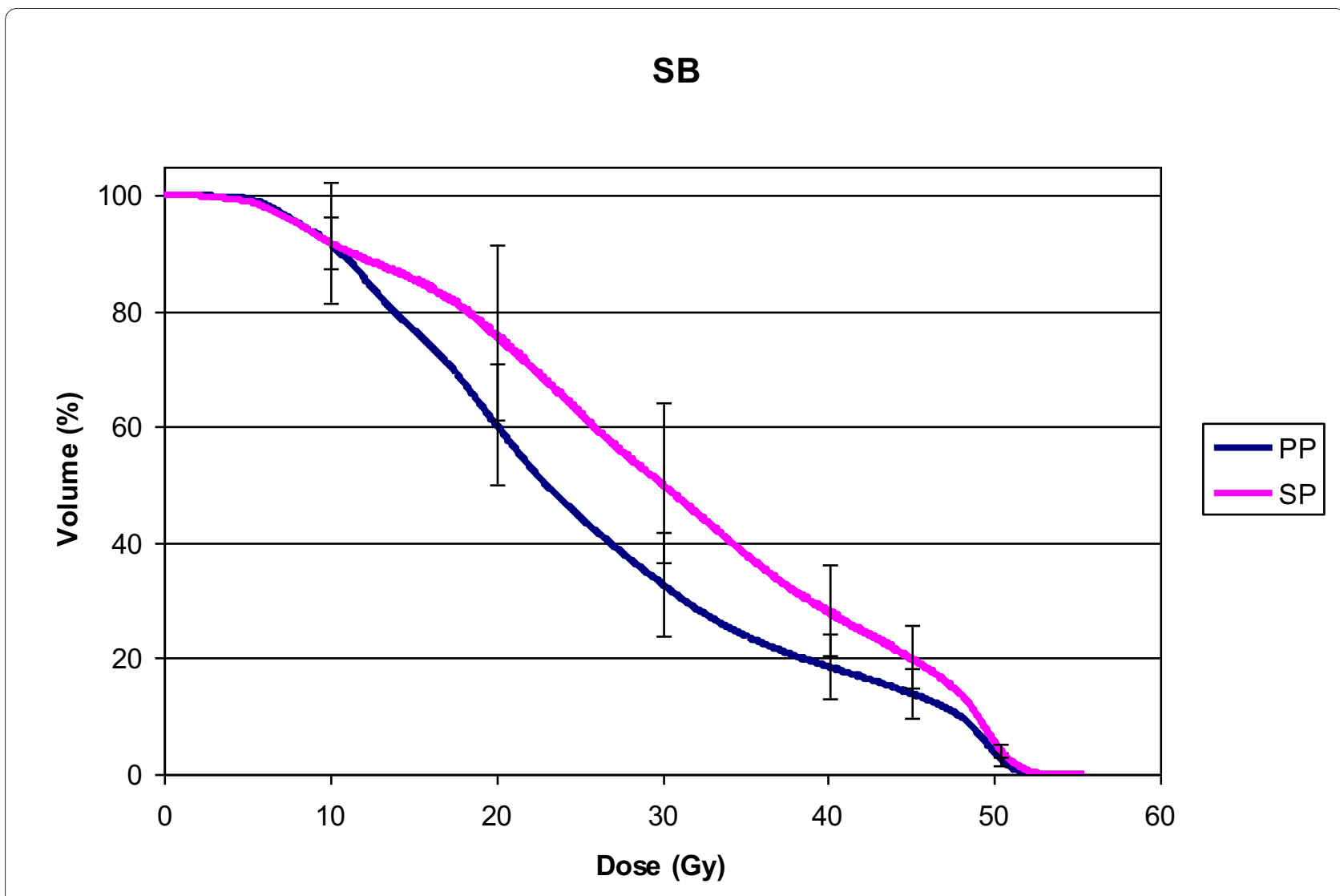

Figure 3 DVH for small bowel. Mean DVH of the small bowel: Supine position (SP, pink) compared to prone position (PP, blue). Error bars indicate the STD. 
254 cc (20\%) for PP and SP, respectively. Roeske and colleagues associated acute bowel morbidity with small bowel volumes receiving $\geq 45 \mathrm{~Gy}$ [29]. Portelance and colleagues [28] showed a significant reduction of the small bowel volume receiving 45 Gy or more with IMRT compared to a 2- and 4-field-technique. Heron and colleagues [26] found a $52 \%$ decrease of the small bowel volume by IMRT.

Few publications addressed the issue of IMRT and the patients' position $[18,48]$. In a planning study performed by Adli and co-workers [48], DVH parameters for two different IMRT techniques (limited arc vs. extended arc) in prone versus supine treatment positions of 16 gynaecologic cancer patients ( 7 postoperative, 9 definitive) were compared. In the present study, we mixed patients with definitive and adjuvant irradiation. George et al. did not see a statistical difference for small bowel sparing in gynaecologic patients with either definitive or adjuvant IMRT treatment in supine position [25]. We therefore pooled patients with primary or postoperative treatments in this planning study, as has been done by others [48].

The prescribed total dose in the study by Adli was 45 Gy, where the small bowel was defined as all individual loops. They observed an anterior movement of small bowel for patients in PP, as we did. A dosimetric benefit was found for PP irrespective of the IMRT techniques. They concluded that the magnitude of small bowel sparing did not merely depend on the prone treatment position, but on the specific IMRT technique used. In our study, we did observe a larger "small bowel" volume (mean $436 \mathrm{cc} ;+35 \%$ ) in PP, evolving from an expansion of the peritoneal cavity not basically due to more small bowel loops but a widening of the space between the loops though the opening in the belly board and an cranial movement of small bowel in supine position. Our small bowel volume for the PP group at 45 Gy and 50.4 Gy was $13.7 \%$ and $2.5 \%$, as compared to the data from Adli and colleagues who saw $12.5 \%$ and 10\% (45 Gy) and $5 \%$ and $6.6 \%$ (50 Gy) for limited arc or extended arc, respectively [48]. Our prescribed dose was slightly higher $\left(D_{\text {mean }} 50.4 \mathrm{~Gy}\right)$, but the sparing of small bowel at V50 was considerable better. The sliding window technique, the 20 MV photon beam and the different contouring of the small bowel might contribute to this volume reduction. Interestingly, Adli and colleagues reported on dose inhomogeneities of up to and over $130 \%$ of the prescribed dose for both IMRT techniques.

No significant dosimetric benefit was seen between PP and SP in a more recently published study by Beriwal and colleagues [18]. They analysed 47 patients with endometrial cancer treated with IMRT. 21 patients were treated in prone and 26 patients in supine position. An inter-individual dosimetric and toxicity comparison was per- formed. The patient cohort was inhomogeneous, 8 patients had pelvic and paraaortic radiotherapy (4 in PP, 4 in SP), 7 patient had chemoradiation (4 in PP, 3 in SP) and the prescribed $D_{\text {mean }}$ ranged form 45-50.4 Gy. All patients received 10 Gy HDR brachytherapy to the vaginal-cuff. Small bowel volumes (defined as the peritoneal surface) at 45 and 50 Gy were remarkably low in PP and SP (V45: $5.8 \%$ and $6 \%$; V50: $1.4 \%$ and $1.2 \%$ ). The IMRT treatment was well tolerated and only one single Grade 3 chronic gastrointestinal toxicity was reported. The authors found no correlation between gastrointestinal morbidity and dosimetric parameters among the opposed set-up positions after a median follow up of 19-20 months. They therefore concluded that a longer follow up is needed to detect any existing differences between the two approaches.

Our aim was to compare the best IMRT 7-field standard technique at our department for the prone position and the supine position. Many factors influence the magnitude of dose reduction to the organs at risk. One key issue is the target volume definition. Large amounts of small bowel are located in the upper pelvic region, around the upper iliac external and common iliac lymph nodes. Our target definition was comparable to those of other authors [25-29]. Furthermore, the contouring of the small bowel is not standardized. Some author's delineated single loops $[25,27,48]$, others preferred to delineate the whole peritoneal cavity $[18,26,28,46]$ as we did. In our study, we did observe a larger "small bowel" volume (mean $436 \mathrm{cc} ;+35 \%$ ) in the prone position, evolving from an expansion of the peritoneal cavity, due not basically to more small bowel loops in the peritoneal cavity but to a widening of the space between the loops through the opening of the belly board. A similar cranial displacement of the small bowel had been observed by Das and colleagues for the prone position [19]. Additionally, the amount of bladder filling might have an impact on uterus motion and consecutively on small bowel motion. Georg and colleagues [25] showed that bladder size correlated with small bowel sparing for definitive pelvic radiotherapy with IMRT in the supine position, but not in patients who had a hysterectomy. In the present study, no emphasis was placed on bladder or rectum filling, and in addition, low planning priority was given for sparing of these organs at risk. Due to these issues of study design, no significant differences in the sparing of the rectum and bladder (exception: V50.4 Gy in PP) could be found. One issue raised against the prone position is the possibility that it is a less reliable and less stable treatment position than the supine one. New data support that the patients' set-up in prone position harbours larger systematic errors, but the set-up in supine position harbours a larger random error [24]. We recommend performing a frequent or even daily on-board imaging with a KV (kilovolt) or MV 
(megavolt) CT to provide the best possible reduction of set-up errors and treatment accuracy when using either position.

\section{Conclusion}

In this dosimetric study, we demonstrated that pelvic IMRT in prone position on a belly board seems to be a useful tool to reduce small bowel volume at a dose $\geq 20$ Gy whilst providing similar target coverage and target conformity for patients with cervical cancer. Despite this, new evidence supports a comparable set-up error for the prone and supine treatment positions. We recommend frequent onboard imaging with KV or MV CTs to assure optimal set-up accuracy. Nevertheless, only outcome studies will show if the dosimetric differences in small bowel sparing will lead to decreased acute and late gastrointestinal toxicity.

\section{Competing interests}

The authors declare that they have no competing interests.

\section{Authors' contributions}

CS did the collection and assembly of data, data analysis and interpretation, and the manuscript writing. SM carried out conception and design, and manuscript writing. YK and TM optimised the IMRT plans. MK and UJ carried out data interpretation. CK and AS helped with the collection of data and to draft the manuscript. VB helped with the interpretation of the data and to draft the manuscript. All authors read and approved the final manuscript.

\section{Acknowledgements}

Our special thanks to Prof. Dr. K. Wernecke for his statistical support.

\section{Author Details}

'Department of Radiooncology, Charité University Hospital, Campus CCM and CVK, Augustenburger Platz 1, 13353 Berlin, Germany and 2Department of Gynaecology, Charité University Hospital, Campus CCM and CBF, Charitéplatz 1, 10117 Berlin, Germany

Received: 26 May 2010 Accepted: 2 July 2010

Published: 2 July 2010

\section{References}

1. Green JA, Kirwan JM, Tierney JF, Symonds P, Fresco L, Collingwood M, Williams CJ: Survival and recurrence after concomitant chemotherapy and radiotherapy for cancer of the uterine cervix: a systematic review and meta-analysis. Lancet 2001, 358:781-786.

2. Hänsgen G, Kuhnt T, Pigorsch S, Strauss H, Dunst J: Adjuvant simultaneous radiochemotherapy after operated uterine cervix carcinoma in high risk situation. Results of a pilot study. Strahlenther Onkol 2002, 178:71-77.

3. Morris M, Eifel PJ, Lu J, Grigsby PW, Levenback C, Stevens RE, Rotman M, Gershenson DM, Mutch DG: Pelvic radiation with concurrent chemotherapy compared with pelvic and para-aortic radiation for high-risk cervical cancer. NEJM 1999, 340:1137-1143.

4. Nagy V, Coza O, Ordeanu C, Trāila A, Rancea A, Todor N, Ghilezan N: Radiotherapy versus concurrent 5 -day cisplatin and radiotherapy in locally advanced cervical carcinoma. Long-term results of a phase III randomized trial. Strahlenther Onkol 2009, 185:177-183.

5. Peters WA, Liu PY, Barrett RJ, Stock RJ, Monk BJ, Berek JS, Souhami L, Grigsby P, Gordon W Jr, Alberts DS: Concurrent chemotherapy and pelvic radiation therapy compared with pelvic radiation therapy alone as adjuvant therapy after radical surgery in high-risk early-stage cancer of the cervix. J Clin Oncol 2000, 18:1606-1613.

6. Rose PG, Bundy BN, Watkins EB, Thigpen JT, Deppe G, Maiman MA, ClarkePearson DL, Insalaco S: Concurrent cisplatin-based radiotherapy and chemotherapy for locally advanced cervical cancer. N Engl J Med 1999, 340:1144-1153.

7. Ryu HS, Chun M, Chang KH, Chang HJ, Lee JP: Postoperative adjuvant concurrent chemoradiotherapy improves survival rates for high-risk, early stage cervical cancer patients. Gynecol Oncol 2005, 96:490-495.

8. Strauss HG, Kuhnt T, Laban C, Puschmann D, Pigorsch S, Dunst J, Koelbl H, Haensgen G: Chemoradiation in cervical cancer with cisplatin and highdose rate brachytherapy combined with external beam radiotherapy. Results of a phase-II study. Strahlenther Onkol 2002, 178:378-385.

9. Whitney CW, Sause W, Bundy BN, Malfetano JH, Hannigan EV, Fowler WC $\mathrm{Jr}$, Clarke-Pearson DL, Liao SY: Randomized comparison of fluorouracil plus cisplatin versus hydroxyurea as adjunct to radiation therapy in stage IIB-IVA carcinoma of the cervix with negative para-aortic lymph nodes: a Gynecology Oncology Group and Southwest Oncology Group study. J Clin Oncol 1999, 17:1339-1348.

10. Andreyev HJ: Gastrointestinal problems after pelvic radiotherapy: the past, the resent and the future. Clin Oncol (R Coll Radiol) 2007, 19:790-799.

11. Kirwan JM, Symonds P, Green JA, Tierney J, Collingwood M, Williams CJ: A systematic review of acute and late toxicity of concomitant chemoradiation for cervical cancer. Radiother Oncol 2003, 68:217-226.

12. Barter JF, Soong SJ, Shingleton HM, Hatch KD, Orr JW Jr: Complications of combined radical hysterectomy-postoperative radiation therapy in women with early stage cervical cancer. Gynecol Oncol 1989, 32:292-296.

13. Landoni F, Maneo A, Colombo A, Placa F, Milani R, Perego P, Favini G, Ferri $L$, Mangioni $C$ : Randomised study of radical surgery versus radiotherapy for stage Ib-lla cervical cancer. Lancet 1997, 350:535-540.

14. Gallagher MJ, Brereton HD, Rostock RA, Zero JM, Zekoski DA, Poyss LF, Richter MP, Kligerman MM: A prospective study of treatment techniques to minimize the volume of pelvic small bowel with reduction of acute and late effects associated with pelvic irradiation. Int J Radiat Oncol Biol Phys 1986, 12:1565-1573.

15. Huang EY, Sung CC, Ko SF, Wang CJ, Yang KD: The different volume effects of small-bowel toxicity during pelvic irradiation between gynecologic patients with and without abdominal surgery: a prospective study with computed tomography-based dosimetry. Int J Radiat Oncol Biol Phys 2007, 69:732-739.

16. Letschert JG, Lebesque JV, de Boer RW, Hart AA, Bartelink H: Dose-volume correlation in radiation-related late small-bowel complications: a clinical study. Radiother Oncol 1990, 18:307-320.

17. Letschert JG, Lebesque JV, Aleman BM, Bosset JF, Horiot JC, Bartelink H, Cionini L, Hamers JP, Leer JW, van Glabbeke M: The volume effect in radiation-related late small bowel complications: results of a clinical study of the EORTC Radiotherapy Cooperative Group in patients treated for rectal carcinoma. Radiother Oncol 1994, 32:116-123.

18. Beriwal S, Jain SK, Heron DE, de Andrade RS, Lin CJ, Kim H: Dosimetric and toxicity comparison between prone and supine position IMRT for endometrial cancer. Int J Radiat Oncol Biol Phys 2007, 67:485-489.

19. Das IJ, Lanciano RM, Movsas B, Kagawa K, Barnes SJ: Efficacy of a belly board device with CT-simulation in reducing small bowel volume within pelvic irradiation fields. Int J Radiat Oncol Biol Phys 1997, 39:67-76.

20. Ghosh K, Padilla LA, Murray KP, Downs LS, Carson LF, Dusenbery KE: Using a belly board device to reduce the small bowel volume within pelvic radiation fields in women with postoperatively treated cervical carcinoma. Gynecol Oncol 2001, 83:271-275.

21. Martin J, Fitzpatrick K, Horan G, McCloy R, Buckney S, O'Neill L, Faul C: Treatment with a belly-board device significantly reduces the volume of small bowel irradiated and results in low acute toxicity in adjuvant radiotherapy for gynecologic cancer: results of a prospective study. Radiother Oncol 2005, 74:267-274.

22. Olofsen-van Acht $M$, van den Berg $H$, Quint $S$, de Boer $H$, Seven $M$, van Sömsen de Koste J, Creutzberg C, Visser A: Reduction of irradiated small bowel volume and accurate patient positioning by use of a bellyboard device in pelvic radiotherapy of gynecological cancer patients. Radiother Oncol 2001, 59:87-93.

23. Pinkawa M, Gagel B, Demirel C, Schmachtenberg A, Asadpour B, Eble MJ: Dose-volume histogram evaluation of prone and supine patient position in external beam radiotherapy for cervical and endometrial cancer. Radiother Oncol 2003, 69:99-105. 
24. Siddiqui F, Shi C, Papanikolaou N, Fuss M: Image-guidance protocol comparison: supine and prone set-up accuracy for pelvic radiation therapy. Acta Oncol 2008, 47:1344-1350.

25. Georg P, Georg D, Hillbrand M, Kirisits C, Pötter R: Factors influencing bowel sparing in intensity modulated whole pelvic radiotherapy for gynaecological malignancies. Radiother Oncol 2006, 80:19-26.

26. Heron DE, Gerszten K, Selvaraj RN, King GC, Sonnik D, Gallion H, Comerci J, Edwards RP, Wu A, Andrade RS, Kalnicki S: Conventional 3D conformal versus intensity-modulated radiotherapy for the adjuvant treatment of gynecologic malignancies: a comparative dosimetric study of dosevolume histograms small star, filled. Gynecol Oncol 2003, 91:39-45.

27. Mundt AJ, Lujan AE, Rotmensch J, Waggoner SE, Yamada SD, Fleming G, Roeske JC: Intensity-modulated whole pelvic radiotherapy in women with gynecologic malignancies. Int J Radiat Oncol Biol Phys 2002, 52:1330-1337.

28. Portelance L, Chao KS, Grigsby PW, Bennet H, Low D: Intensitymodulated radiation therapy (IMRT) reduces small bowel, rectum, and bladder doses in patients with cervical cancer receiving pelvic and para-aortic irradiation. Int J Radiat Oncol Biol Phys 2001, 51:261-266.

29. Roeske JC, Lujan A, Rotmensch J, Waggoner SE, Yamada D, Mundt AJ: Intensity-modulated whole pelvic radiation therapy in patients with gynecologic malignancies. Int J Radiat Oncol Biol Phys 2000, 48:1613-1621.

30. Ahmed RS, Kim RY, Duan J, Meleth S, De Los Santos JF, Fiveash JB: IMRT dose escalation for positive para-aortic lymph nodes in patients with locally advanced cervical cancer while reducing dose to bone marrow and other organs at risk. Int J Radiat Oncol Biol Phys 2004, 60:505-512.

31. D'Souza WD, Ahamad AA, lyer RB, Salehpour MR, Jhingran A, Eifel PJ: Feasibility of dose escalation using intensity-modulated radiotherapy in posthysterectomy cervical carcinoma. Int J Radiat Oncol Biol Phys 2005, 61:1062-1070

32. Vandecasteele K, De Neve W, De Gersem W, Delrue L, Paelinck L, Makar A, Fonteyne V, De Wagter C, Villeirs G, De Meerleer G: Intensity-modulated arc therapy with simultaneous integrated boost in the treatment of primary irresectable cervical cancer. Treatment planning, quality control, and clinical implementation. Strahlenther Onkol 2009, 185:799-807.

33. Beriwal S, Gan GN, Heron DE, Selvaraj RN, Kim H, Lalonde R, Kelley JL, Edwards RP: Early clinical outcome with concurrent chemotherapy and extended-field, intensity-modulated radiotherapy for cervical cancer. Int J Radiat Oncol Biol Phys 2007, 68:166-171.

34. Chen MF, Tseng CJ, Tseng CC, Kuo YC, Yu CY, Chen WC: Clinical outcome in posthysterectomy cervical cancer patients treated with concurrent Cisplatin and intensity-modulated pelvic radiotherapy: comparison with conventional radiotherapy. Int J Radiat Oncol Biol Phys 2007, 67:1438-1444.

35. Chen MF, Tseng CJ, Tseng CC, Yu CY, Wu CT, Chen WC: Adjuvant concurrent chemoradiotherapy with intensity-modulated pelvic radiotherapy after surgery for high-risk, early stage cervical cancer patients. Cancer J 2008, 14:200-206.

36. Marnitz S, Köhler C, Roth C, Füller J, Bischoff A, Wendt T, Schneider A Budach V: Stage-adjusted chemoradiation in cervical cancer after transperitoneal laparoscopic staging. Strahlenther Onkol 2007, 183:473-478.

37. International Commision on Radiation Units and Measurements: Prescribing, recording and reporting photon beam therapy. ICRU Report 50. Bethesda 1993.

38. International Commission on Radiation Units \& Measurements: Supplement to ICRU Report 50, ICRU Report 62. Bethesda 1999.

39. Radiation Therapy Oncology Group [http://www.rtog.org/

40. Marnitz S, Köhler C, Schneider A, Seiler F, Hinkelbein W: Interindividual variability of lymph drainages in patients with cervical cancer. Implication on irradiation planning. Strahlenther Onkol 2006, 182:80-85.

41. van't Riet A, Mak AC, Moerland MA, Elders LH, van der Zee W: A conformation number to quantify the degree of conformality in brachytherapy and external beam irradiation: application to the prostate. Int J Radiat Oncol Biol Phys 1997, 37:731-736.

42. Marnitz S, Köhler C, Füller J, Hinkelbein W, Schneider A: Uterus necrosis after radiochemotherapy in two patients with advanced cervical cancer. Strahlenther Onkol 2006, 182:45-51.
43. Füller J, Guderian D, Köhler C, Schneider A, Wendt TG: Lymph edema of the lower extremities after lymphadenectomy and radiotherapy for cervical cancer. Strahlenther Onko/ 2008, 184:206-211.

44. Bouchard M, Nadeau S, Gingras L, Raymond PE, Beaulieu F, Beaulieu L, Fortin A, Germain I: Clinical outcome of adjuvant treatment of endometrial cancer using aperture-based intensity-modulated radiotherapy. Int J Radiat Oncol Biol Phys 2008, 71:1343-1350.

45. Gerszten K, Colonello K, Heron DE, Lalonde RJ, Fitian ID, Comerci JT, Selvaraj RN, Varlotto JM: Feasibility of concurrent cisplatin and extended field radiation therapy (EFRT) using intensity-modulated radiotherapy (IMRT) for carcinoma of the cervix. Gynecol Oncol 2006, 102:182-188.

46. Mundt AJ, Mell LK, Roeske JC: Preliminary analysis of chronic gastrointestinal toxicity in gynecology patients treated with intensitymodulated whole pelvic radiation therapy. Int J Radiat Oncol Biol Phys 2003, 56:1354-1360.

47. Salama JK, Mundt AJ, Roeske J, Mehta N: Preliminary outcome and toxicity report of extended-field, intensity-modulated radiation therapy for gynecologic malignancies. Int J Radiat Oncol Biol Phys 2006, 65:1170-1176

48. Adli M, Mayr NA, Kaiser HS, Skwarchuk MW, Meeks SL, Mardirossian G, Paulino AC, Montebello JF, Gaston RC, Sorosky Jl, Buatti JM: Does prone positioning reduce small bowel dose in pelvic radiation with intensitymodulated radiotherapy for gynecologic cancer? Int J Radiat Oncol Biol Phys 2003, 57:230-238

doi: 10.1186/1748-717X-5-63

Cite this article as: Stromberger et al., Intensity-Modulated Radiotherapy in Patients with Cervical Cancer. An intra-individual Comparison of Prone and Supine Positioning Radiation Oncology 2010, 5:63

\section{Submit your next manuscript to BioMed Central and take full advantage of:}

- Convenient online submission

- Thorough peer review

- No space constraints or color figure charges

- Immediate publication on acceptance

- Inclusion in PubMed, CAS, Scopus and Google Scholar

- Research which is freely available for redistribution
C) BioMed Central 